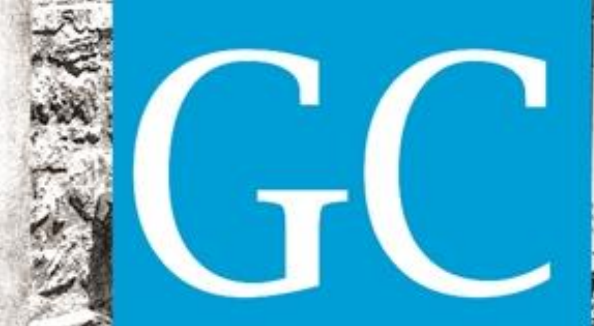

Revista Nacional de

Gerenciamento de Cidades

\title{
Políticas e práticas territoriais socialmente necessárias
}

Socially necessary territorial policies and practices

Políticas y prácticas territoriales socialmente necesarias

Manoel Lemes da Silva Neto

Professor Titular da Faculdade de Arquitetura e Urbanismo e do Programa de Pós-Graduação em Arquitetura e Urbanismo, PUC-Campinas ladeur@ladeur.com.br

Fabiano Melo Gonçalves de Oliveira Doutor em Urbanismo, Programa de Pós-Graduação em Arquitetura e Urbanismo, PUC-Campinas fabianomg@gmail.com

Thiago Carandina

Doutorando em Urbanismo, Programa de Pós-Graduação em Arquitetura e Urbanismo, PUC-Campinas carandinath@hotmail.com 


\section{RESUMO}

O objetivo é discutir a insuficiência das condições por meio das quais os instrumentos da legislação urbanística são formulados e postos em prática. Parte-se do pressuposto de que há condições históricas que podem contribuir, e até mesmo produzir, arcabouços normativos com horizontes democráticos concretos, amplos, e sob perspectiva redistributiva. A existência de pré-condições históricas para a constituição do Período Popular da História, propõe planos analíticos inovadores, a exemplo da noção elementar do "socialmente necessário". Esses elementos fundamse na compreensão do "território usado" como instância ativa da sociedade e categoria analítica essencial para se pensar o futuro. Examina-se os limites históricos que conduzem análises, projetos e planos que orbitam em torno da noção seminal do "direito à cidade", e especula-se sobre a urgência de se pensar os lugares como dimensão políticoinstitucional imprescindível para alçar o direito ao patamar do socialmente necessário. Para a apreensão de possibilidades concretas, de natureza insurgente e que se apresentam no presente histórico, especula-se sobre interrelações indissociáveis e socialmente necessárias dos agentes sociais no processo de tomada de decisões das políticas públicas de caráter territorial.

PALAVRAS-CHAVE: Política urbana. Atores sociais. Ação política. Território usado. Período popular da história.

\section{ABSTRACT}

The objective is to discuss the insufficiency of the conditions through which the instruments of urban planning legislation are formulated and put into practice. It is based on the assumption that there are historical conditions that can contribute, and even produce, normative frameworks with concrete, broad democratic horizons and redistributive perspectives. The existence of pre historic conditions for the constitution of the Popular Period of History, propose innovative analytical plans, for example in the elementary notion of "socially necessary". These elements are based on the understanding of "used territory" as an active instance of society and an analytical category essential for thinking to the future. It examines the historical limits that lead to analyzes, projects and plans that revolve around the seminal notion of the "right to the city" and speculated about the urgency to think places like political-institutional dimension essential to achieve the right to level socially necessary. In order to understand concrete possibilities of an insurgent nature and that present themselves in the historical present, it is speculated on the inseparable and socially necessary interrelations of the social agents in the decision-making process of public policies of a territorial character.

KEYWORDS: Urban policy. Social actors. Political action. Used territory. Popular period of history.

\section{RESUMEN}

El objetivo es discutir la insuficiencia de las condiciones por medio de las cuales los instrumentos de la legislación urbanística son formulados y puestos en práctica. Se parte del supuesto de que hay condiciones históricas que pueden contribuir, e incluso producir, estructuras normativas con horizontes democráticos concretos, amplios, y bajo perspectiva redistributiva. La existencia de precondiciones históricas para la constitución del Período Popular de la Historia, propone planes analíticos innovadores, a ejemplo de la noción elemental del "socialmente necesario". Estos elementos se fundan en la comprensión del "territorio usado" como instancia activa de la sociedad y categoría analítica esencial para pensar el futuro. Se examinan los límites históricos que conducen análisis, proyectos y planes que orbitan en torno a la noción seminal del "derecho a la ciudad", y se especula sobre la urgencia de pensar los lugares como dimensión político-institucional imprescindible para alzar el derecho al, de la socialmente necesaria. Para la aprehensión de posibilidades concretas, de naturaleza insurgente y que se presentan en el presente histórico, se especula sobre interrelaciones indisociables y socialmente necesarias de los agentes sociales en el proceso de toma de decisiones de las políticas públicas de carácter territorial.

PALABRAS CLAVE: Política urbana. Actores sociales. Acción política. Territorio utilizado. Período popular de la historia. 


\section{SOBRE O SOCIALMENTE NECESSÁRIO}

"Território usado" (SANTOS, 1999; 2000) e "mercado socialmente necessário" (RIBEIRO, 2005) são conceituações decorrentes da reorientação epistemológica da noção de espaço geográfico proposta por Milton Santos ((1996) 2006). Por meio da análise do mundo contemporâneo em sua totalização no fenômeno territorial, a teoria social crítica contextualiza fundamentalmente a constituição do atual "meio técnico-científico-informacional" ${ }^{1}$, meio em que, com o advento da globalização, produz as pré-condições necessárias ao surgimento de novo período histórico: o "popular" ou "demográfico"2 (SANTOS, 2000).

Nessa direção, as práticas e políticas territoriais socialmente necessárias corresponderiam às possibilidades de se balizar uma forma de planejamento: o socialmente necessário. Se o planejamento for compreendido no rol das "técnicas de controle social" (MANNHEIM, 1940, apud PEREIRA, 1970, p. 14), as práticas e políticas socialmente necessárias definem-se na medida em que o controle social deriva da dualidade do agente Estado-Mercado para o Território, só que alçado à instância ativa da sociedade, "como a economia, a cultura e a política" (SOUZA, 2005, p. 252) . O planejamento socialmente necessário reforça o controle socioterritorial da ação política na organização do espaço humano, acenando, com isso, possíveis históricos potencialmente libertários.

Do ponto de vista do planejamento territorial, pode-se dizer que essa outra possibilidade corresponde, grosso modo, ao que Boisier denominou como "paradigma construtivista/complexo", e em confronto ao neoliberalizante "paradigma positivista/analítico" (1988, apud SILVA NETO, 2003, p. 368-369). O planejamento, então, poderia "ser identificado como uma 'engenharia de intervenções territoriais' e as regiões, como os edifícios, 'espaços

\footnotetext{
1 "A fase atual (...) é o momento no qual se constitui, sobre territórios cada vez mais vastos, o que se chamará de meio técnico-científico, isto é, o momento histórico no qual a construção ou reconstrução do espaço se dará com um crescente conteúdo de ciência e de técnicas. (...) A partir, sobretudo, do fim da Segunda Guerra Mundial, generalizase a tendência. Desse modo, as remodelações que se impõem, tanto no meio rural, quanto no meio urbano, não se fazem de forma indiferente quanto a esses três dados: ciência, tecnologia e informação." (Santos, 1994, p.139). Em obra mais recente, Milton Santos propõe designar o "período industrial" em "período técnico" (1996, p. 188-190) e o "técnico-científico" em "técnico-científico-informacional" (1996, p.190-192).

2 "A gestação do novo, na história, dá-se, freqüentemente, de modo quase imperceptível para os contemporâneos, já que suas sementes começam a se impor quando ainda o velho é quantitativamente dominante. É exatamente por isso que a 'qualidade' do novo pode passar despercebida. (...) No caso do mundo atual, temos a consciência de viver um novo período, mas o novo que mais facilmente apreendemos é a utilização de formidáveis recursos da técnica e da ciência pelas novas formas do grande capital, apoiado por formas institucionais igualmente novas. (...) Uma das conseqüências de tal evolução é a nova significação da cultura popular, tornada capaz e rivalizar com a cultura de massas, apontando para o surgimento de um novo período histórico, a que chamamos de período demográfico ou popular (M. Santos, Espaço e sociedade, 1979)" (SANTOS, 2000, p. 141-143).

3 "Elaborando sobre o espaço geográfico, objeto da geografia, propondo que ele seja considerado uma instância social, como a economia, a cultura e a política [Milton Santos] vai revolucionar nossa disciplina. Vai dar ao espaço geográfico um estatuto teórico e, com isso, uma possibilidade até então inexistente de aprofundamento do diálogo entre a Geografia e as demais disciplinas do conhecimento. Vai propor que o espaço geográfico, sinônimo de território usado seja assumido como um conceito indispensável para a compreensão do funcionamento do mundo do presente, este mundo dominado pela globalização, esta metáfora que incansavelmente torna míope a realidade da maioria dos habitantes da Terra" (SOUZA, 2005, p. 252).
} 
Norma jurídica que em seu constitutivo possui como características a generalidade, a abstração e a coerção. Isto é, norteia-se para um homem genérico, ideal, insculpido em um dever-ser sempre presente nas formulações jurídicas (OLIVEIRA, 2017). Essa conjugação por vezes desconhece, por vezes procura minimizar a complexidade dos diferentes contextos sociais, "fortalece o caráter modelar, universalista e abstrato do direito e do urbanismo" (RIBEIRO, 2013, p. 225) e constitui ameaça ao pensamento crítico contemporâneo. Isso porque a generalidade e abstração permitem a concepção de leis e "códigos que anulam a experiência popular e as estratégias de sobrevivência dos mais pobres" (RIBEIRO, 2013, p. 226). Com a falta de intercâmbio democrático de valores, enrijece as relações entre lei e práticas sociais (RIBEIRO, 2013a).

Instrumentos e experiências socialmente necessários esbarram-se em um humanismo abstrato, de categorias e enunciados, que mistificam ou mascaram um quadro de desigualdades.

Lutas urbanas são reivindicatórias, exigências para contemplar direitos nas constituições e codificações. Necessárias, mas que, na maioria das vezes, não passam do reconhecimento no plano formal, pois entre a norma posta e a realidade encontra óbices como a ausência de efetividade, a omissão na execução e a fragmentação de direitos, com a sonegação da compreensão de totalidade, da vivência e da experiência de direitos enquanto um núcleo de dignidade (OLIVEIRA, 2017).

Essa conjugação constitui um impeditivo dos direitos socialmente necessários.

Com o avanço do ideário neoliberal, aquilo que já era frágil sofre o influxo de direitos, quando maiorias parlamentares pontuais - dominadas pela plutocracia - utilizam do processo legislativo ordinário - por vezes em detrimento dos desígnios constitucionais - para a consecução de diplomas legais que desterritorializam populações ou que olvidam ou descartam as vivências, experiências e contextos socioculturais em nome dos reclamos do mercado e de uma "destruição criativa" (HARVEY, 2007). Impõe-se às maiorias socialmente vulneráveis as restrições de direitos e o custo de políticas financeiras, sob o manto da abstração e uma suposta generalidade da norma jurídica, que pouco afeta aqueles que estão no "andar de cima" dos estratos sociais (SANTOS, 2006).

O Direito à Cidade - Uma expressão é amiúde nos reclamos de militantes e intelectuais do universo urbano: o direito à cidade, originalmente proposta na obra homônima de Henri Lefebvre ((1968) 2011).

Diante das relações jurídicas de ordem privatista, de prevalência do valor de troca sobre o valor de uso, cidades construídas e reconstruídas sob a ótica dos interesses das classes hegemônicas, de índole liberal, nunca formando institutos jurídicos criadores de um sistema público, que estabeleça e contemple a ocupação de espaços para todas as classes sociais, Lefebvre concebe o que chamou de direito à cidade, como um direito à vida urbana, transformada, renovada, em um novo humanismo com uma nova práxis e um novo homem (LEFEBVRE, 2004). 


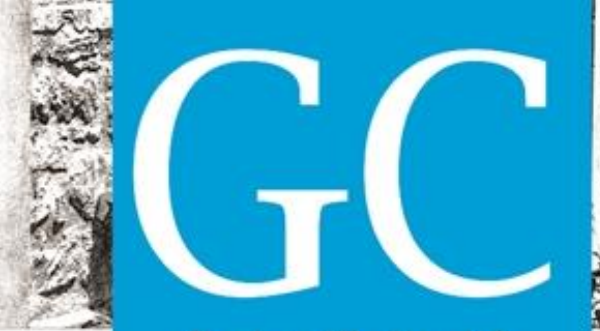

Revista Nacional de

Gerenciamento de Cidades

planejadores/tecnocratas. Resultado. Nesse contexto o sujeito social fica à margem de todo processo. E o mais incerto. O poder explicativo e propositivo do modelo vê-se prejudicado por não considerar o território como instância ativa da sociedade (SOUZA, 2005; SILVA NETO, 2014); a seleção deliberada do projeto de alguns sobre o interesse de todos enquadra-se naquela classe de protagonismo pela qual o ator social se impõe sobre a problemática do sujeito, que é mais complexa e estrutural (RIBEIRO (2011).

Segundo Milton Santos (1996), o entorno no qual se instalam as formas naturais e artificiais, assim como, as relações compulsórias ou espontâneas, sentimentos, valores e ideias é que determina o valor real, criando novas localizações, divisões de trabalho e formas de cooperação.

\section{CONCLUSÕES}

O Escritório Público de Salvador já entregou cinco mil projetos. A cidade de São Paulo possui $498,3 \mathrm{~km}$ de vias com tratamento cicloviário permanente, sendo $468,0 \mathrm{~km}$ de ciclovias ou ciclofaixas e $30,3 \mathrm{~km}$ de ciclorrotas. A integração modal conta com 6.149 vagas em bicicletários públicos, e 121 paraciclos públicos instalados nos Terminais de Ônibus e nas Estações de Trem e Metrô (CET, 2018).

Como forma de induzir o adensamento populacional e habitacional nos eixos de transporte dotados com maior infraestrutura, a LPUOS de São Paulo fixou a cota parte 30. Com isso impede, ou dificulta, que a verticalização agregue a vantagem comparativa resultante da oferta das melhores infraestruturas no mercado imobiliário de edifícios elitizados.

Itaú Cultural, Sesc, Instituto Moreira Salles somam-se ao MASP construindo grandes e importantes arquiteturas devotadas à população em geral no eixo coletivizado da avenida Paulista - em finais de semana e feriados a via é fechada aos veículos. Esse "fechamento" também ocorre em outras grandes avenidas da cidade.

Formações temporárias, elas não têm o mesmo sentido da convivência em parques e jardins públicos, que, se diga, estão em vias de serem privatizados pela gestão municipal vigente.

São diferentes dos espaços públicos do projeto urbanístico.

Reúnem o encontro e o acesso facilitado pela rede de transporte público, em especial, a metroviária.

Há trinta anos essa concepção de projeto urbano seria incompreensível, ou radicalmente rechaçada. Há, hoje, praticadas, sociabilidades e corporalidades que reúnem os cidadãos em trocas de variadas naturezas. E essas demonstrações podem ser interpretadas como evidências de pré-condições históricas para constituição do período popular da história. Com ele, as "coisas" socialmente necessárias.

De fato, o território usado pode ser vivenciado. Concretamente. Não repousa no campo da especulação teórica. É experimentado, e por grande número. O período popular da história também é reconhecido por ser um período demográfico. Há, aí, o poder do número. 
O território usado, o território banal, o espaço de todos, por um "capricho" da história, passa por ter seu reconhecimento normativo exatamente porque, por ser "comum", nada mais faz que cumprir o que reza a lei. $O$ interesse comum relativiza e subordina o interesse particular. Seguimos.

\section{REFERÊNCIAS}

BOISIER, Sérgio. Palimpsesto de las regiones como espacios socialmente construtivos. Cuaderno n. 2. ILPES, Santiago de Chile, 1988.

CADERNOS IPPUR. UFRJ/Instituto de Pesquisa e Planejamento Urbano e Regional da Universidade do Rio de Janeiro. Rio de Janeiro, 2006, v. XX, n.1, p. 49-75, jan./jul. 2006.

CARANDINA, Thiago; SILVA NETO, Manoel Lemes da. Geometrias e geografias, modelos e territórios. In: Regional Studies Association - Latin America Division Conference 2017. Brazil 2017 Papers. São Paulo: RSA, 2017. Disponível em: < http://www.regionalstudies.org/

conferences/presentations/brazil-2017-papers>. Acesso em: 25 set. 2017.

CONSELHO DE ARQUITETURA E URBANISMO (CAU). Arquitetura social: escritório público de salvador já entregou 5 mil projetos. Disponível em: <http://www.caubr.gov.br/escritorio-publico-salvador/>. Acesso em: 17 abr. 2018

FAORO, Raymundo. Os donos do poder: formação do patronato político brasileiro. 3 ed. São Paulo: Globo, 2001.

GIVISIEZ, Gustavo Henrique Naves; OLIVEIRA, Elzira Lúcia de. Privacidade intradomiciliar: um estudo sobre as necessidades de ampliações em residências, Revista Brasileira de Estudos Populacionais. Rio de Janeiro, v. 30, n. 1, p. 199-223, jan./jun. 2013.

HAESBAERT, Rogério. O Mito da Desterritorialização: Do "Fim dos Territórios" à Multiterritorialidade. 7. ed. Rio de Janeiro: Bertrand Brasil, 2012.

HARVEY, David. Cidades Rebeldes: do Direito à Cidade à Revolução Urbana. São Paulo: Martins Fontes, 2014.

HARVEY, David. Condição Pós-Moderna. 16. ed. São Paulo: Loyola, 2007.

LATOUR, Bruno. Jamais formos modernos. Rio de Janeiro: Editora 34, 2013.

LEFEBVRE, Henri. A Revolução Urbana. Belo Horizonte: Editora da UFMG, 2004.

LEFEBVRE, Henri. O Direito à Cidade. São Paulo: Centauro, 2011.

LEFEBVRE, Henri. Sociologia de Marx. Rio de Janeiro: Forense, 1979.

LEVY, Jacques. Penser la ville: un imperatif sous toutes les latitudes. Cahiers d'Etudes sur la Méditerranée Orientale et le monde Turco-Iranien, 24, 1997. Disponível em: <https://journals.openedition.org/ cemoti/1458>. Acesso em: 15 ago. 2016.

MAIA, Camila Barreto. Que impactos esperar da participação na elaboração de políticas públicas? Proposta de um conjunto de critérios para avaliar o processo participativo do Plano Diretor de São Paulo. Dissertação (Mestrado) Escola de Administração de Empresas de São Paulo da Fundação Getulio Vargas. São Paulo, 2016.

MARCUSE, Peter. From critical urban theory to the right to the city. CITY, VOL. 13, NOS. 2-3, JUNE-SEPTEMBER 2009. 
MARCUSE, Peter. Whose right(s) to what city? In: BRENNER, Neil; MARCUSE, Peter; MAYER, Margit. Citis for people, not for profit. London: Routledge, 2012.

MORIN, Edgar. A cabeça bem feita: repensar a reforma, reformar o pensamento. Rio de janeiro: Bertrand Brasil, 2002.

MONTANDON, Daniel. Revisão do Zoneamento em São Paulo: o que está em jogo? São Paulo: Mackenzie, 2018.

NAÏR, Sami.; MORIN, Edgar. Uma política de civilização. Lisboa: Instituto Piaget, s.d..

NAKANO, Anderson Kazuo. Elementos demográficos sobre a densidade urbana da produção imobiliária: São Paulo, uma cidade oca? Tese (Doutorado) - Instituto de Filosofia e Ciências Humanas, Universidade Estadual de Campinas.Campinas, 2015.

OLIVEIRA, Fabiano Melo G. O direito à cidade. Relatório de Qualificação. Campinas: Pontifícia Universidade Católica de Campinas, 2017.

PEREIRA, Luiz. Ensaios de sociologia do desenvolvimento. 3 ed. São Paulo: Pioneira, 1970. (Biblioteca Pioneira de Ciências Sociais).

RIBEIRO, Ana Clara Torres et al. Por uma cartografia da ação: pequeno ensaio de método. Cadernos IPPUR, a. XV, n. $2,2001$.

RIBEIRO, Ana Clara Torres. Território usado e humanismo concreto: o mercado socialmente necessário. In: Silva, Catia Antonia da et al. Formas em crise: utopias necessárias. Rio de Janeiro: Arquimeds Edições, 2005, p. 93-111.

RIBEIRO, Ana Clara Torres. Dimensões culturais da ilegalidade. In: Por uma Sociologia do Presente: ação, técnica e espaço. Volume 4. Rio de janeiro: Letra Capital, 2013, p. 223-238.

RIBEIRO, Ana Clara Torres. Sujeito corporificado e bioética: caminhos da democracia. In: Por uma Sociologia do Presente: ação, técnica e espaço. Volume 2. Rio de janeiro: Letra Capital, 2013a.

RIBEIRO, Ana Clara Torres. Lugares de los saberes: diálogos abiertos. Por uma sociologia do presente: ação, técnica e espaço. Rio de Janeiro: Letra Capital, 2013b. p. 17-28.

RIBEIRO, Ana Clara Torres. Teorias da ação. Rio de Janeiro: Letra Capital, 2014.

RONCA, José Luís Caruso. Desenvolvimento regional: o caso da SUDENE. In: Bruna, Gilda Collet. (Org.). Questões de Organização do Espaço Regional. São Paulo: Livraria Nobel S/A e Ed. da Universidade de São Paulo, 1983, p. 175-213.

SANTOS JÚNIOR, Orlando Alves. Espaços Urbanos Coletivos, Heterotopia e o direito à cidade: Reflexões a partir do pensamento de Henri Lefebvre e David Harvey. In: Teorias e Práticas Urbanas. Belo Horizonte: C/Artes, 2015.

SANTOS, Boaventura de Souza (org.). Democratizar a democracia: caminhos da democracia participativa. Rio de Janeiro: Civilização Brasileira, 2002.

SANTOS, Milton. Técnica, espaço, tempo: globalização e meio técnico-científico informacional. São Paulo: Hucitec,1994. (Geografia: teoria e realidade).

SANTOS, Milton. As cidadanias mutiladas. In: LERNER, Julio (Ed.). O preconceito. São Paulo: Imprensa Oficial do Estado de São Paulo, 1996/1997, p. 133-144.

SANTOS, Milton. A natureza do espaço: técnica e tempo; razão e emoção. São Paulo: Hucitec, 1996.

SANTOS, Milton. A natureza do espaço: técnica e tempo, razão e emoção, São Paulo: Edusp, (1996) 2006. 
